\title{
Toroppalan $t$
}

Toroppalan kylä, joka vanhastaan kuului Kerimäen pitäjään mutta siirtyi vuonna 2013 kuntaliitoksessa osaksi Savonlinnaa, on kuuluisa murteestaan. Murteen erityispiirteenä on normaalia takaisempana ääntyvä, alveolaarinen $t$, jota kansanomaisesti sanotaan Doroppalan d:ksi. Kyseisen murteen puhumista luonnehditaan dödöttämiseksi. Tutustuin Toroppalan $t$ :hen ensimmäistä kertaa elokuussa 1987, jolloin kävin tutkija Jaakko Yli-Paavolan kanssa varta vasten kuulostelemassa $t$ :tä Toroppalan kylässä. Takainen $t$ oli tuolloin havaittavissa monenikäisillä kyläläisillä, myös lapsilla. (Palander 1993: 232233.) Toistamiseen vierailin Toroppalassa maaliskuussa 2017, tällä kertaa toimittaja Sakari Silvolan kanssa, joka halusi tehdä aiheesta tiedeohjelman televisioon. Takaista $t$ :tä saattoi edelleen kuulla useimpien haastattelemiemme kyläläisten murteessa.

Tarkoitukseni on tässä kirjoituksessa kuvata Toroppalan $t$ :n murremaantieteellistä ja sosiolingvististäkin asemaa. Samalla pohdin sitä, mitä voidaan päätellä piirrettä koskevista kansanlingvistisistä havainnoista ja julkisuuskuvasta, sekä sitä, millaiselta ilmiön tulevaisuus näyttää.

\section{Suppealevikkinen murrepiirre}

Toroppala kuten koko Kerimäki kuuluu Savonlinnan seudun välimurteisiin ja edustaa savolaismurteita (ks. karttaa 1 seur. sivulla). Alueen murre on syntynyt vanhasta karjalaisesta kielimuodosta, joka on savolaistunut savolaisekspansion myötä 150o-luvulta lähtien (Palander 1996: 26-32). Kerimäen saarento, joka käsit- tää entisen Kerimäen lisäksi Enonkosken ja Savonrannan eteläosat, Säämingin itälaidan sekä Punkaharjun pohjoisreunan, on murteeltaan yhtenäisempää kuin muu murreryhmä, vaikkakin koko murteistolle on ominaista runsas alueellinen, idiolektien välinen ja jopa idiolektin sisäinen vaihtelu (Palander 2001). Vanhat karjalaispohjaiset ja myöhemmät savolaiset variantit ovat kauan eläneet murteessa rinnakkain mutta synnyttäneet myös kontaminaatiomuotoja, joiden levikkialue on verrattain suppea. Tällaisia ovat esimerkiksi antoissa, kynteissä -tyyppiset 2. infinitiivin inessiivimuodot, joihin ovat vaikuttaneet yhtäältä karjalaiset antoaśśa andoaśśa, kynteäśśä kyndeäsśä -muodot ja toisaalta savolainen antaissa, kyntäissä -muototyyppi. (Palander 1996: 313-317.)

Toroppalan takaisen $t$ :n syntyä ei voi tarkasti selvittää, sillä tällaisista foneettisista piirteistä ei jää jälkiä vanhoihin asiakirjoihin. Toroppala on Kerimäen suurpitäjän vanhimpia kyliä: Toropanaho esiintyy vuoden 1561 verollepanomaakirjassa (Mielonen 1993: 20), ja Laurentz Röösin karttakirjassa (MHA C:1), joka on laadittu vuosina 1643-1644, Toroppala mainitaan jo kylänä (Toropala B̈̈). Kylä on saanut nimensä ensimmäisistä asukkaistaan, Toropaisista, jotka ovat olleet ortodoksisukua ja tulleet alueelle idästä, Laatokan Karjalasta (Mielonen mts. 20-22). Takaisena ääntyvä $t$ periytyy murteen savolaiskerrostumasta. Savolaisartikulaatiolle on ominaista ylipäätään takaisuus (Sarvas 1980: V): esimerkiksi $\ddot{a}$-vokaalit ääntyvät paikoin PohjoisKarjalassa niin takaisina, että ne ovat synnyttäneet liioittelevia idiolektimatkimuksia (esim. nain 'näin'; Mielikäinen \& Palander 


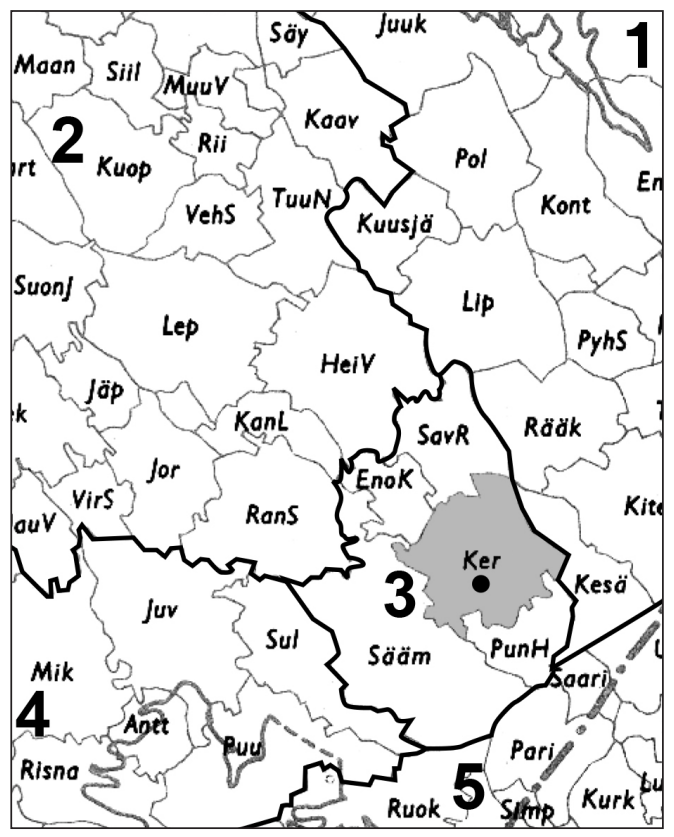

Kartta 1.

Kerimäki murrekartalla. 1 = Pohjois-Karjalan murteet, 2 = Pohjois-Savon murteet, 3 = Savonlinnan seudun välimurteet, 4 = Etelä-Savon murteet, 5 = kaakkoismurteet. Toroppalan sijainti on merkitty mustalla umpiympyrällä.

2014b: 216; ks. myös Nahkola 1998: 24). Toroppalan takainen $t$ voikin olla useita sukupolvia vanha savolaisuus.

Takaista $t$ :tä voidaan pitää paikallisena murrepiirteenä sikäli, että Toroppalassa äänne on esiintynyt 180o-luvun lopulla ja 1900-luvun alussa syntyneiden kielessä. Suomen kielen nauhoitearkistossa Kerimäeltä on murrenäytteitä neljältä syntyperäiseltä toroppalalaiselta, ja takaista $t$ :tä (merkitty seuraavassa $D: 11$ ä) on jossain määrin kuultavissa niistä kolmessa (esim. 1a-c, 2a-b, 3a-b), vaikkakaan ei säännöllisesti (esim. 1d, 2c, 3c-d):

(1) a. isänDä ol', Juvala

b. vii e àekaa Dö'ehej ja yheksä àekaa, pòes

c. tunDi kummallaik kerrala ol'

d. se sano rovastile: jumalato', armahtaa juhtoosa
(SKNA 3544:2; esimerkit 1a-d kuunneltavissa Verkko-Virittäjässä)

(2) a. missä nyt on Dää Doroppalay koulu

b. on ollum monellaista ilemoo ja, tyyndä ja tuulDa ja

c. siinä asuttii sitte, yheksäntoista vuotta

(SKNA 8256:1a)

(3) a. mutta mèiDä, meiD_ol' kaks tyttöö siinä

b. kyllä vinkasivat lähDiissä. ja kun ne Viipurissa sillon Dekikiip pahojaam paljo

c. mèil_ol' vihta aina, taskussa tahikka käissä

d. nää on tämmosi a rakki a

(SKNA 9169:1a) 
Näytteiden informanteissa on sekä miehiä että naisia, ja $D$ :tä esiintyy kummallakin sukupuolella. Tarkemmin tutkimatta on vaikea sanoa, onko takaisen $t$ :n esiintyminen yhteydessä tiettyihin äänne- tai tavuasemiin.

Suppealevikkisiä murrepiirteitä on voinut kehittyä entisaikoina, jolloin ihmiset syntyivät, elivät ja kuolivat samassa kylässä ja kontaktit kylän ulkopuolelle olivat satunnaisia. Kun puhekielen malli pysyi sukupolvesta toiseen melko samanlaisena, ääntämys sai vahvistusta sekä omasta perhepiiristä että lähiympäristöstä. Suomen murteissa on lukuisia muitakin ilmiöitä, jotka rajoittuvat vain yhteen tai korkeintaan muutamaan pitäjään. Lauri Kettusen murrekartaston (1940a) 213:sta äänne-, muoto- ja sanastopiirteitä esittelevästä levikkikartasta noin 25:ssä on merkitty vain yhdessä pitäjässä tavattavia variantteja, kuten uatura 'aura' Hirvensalmelta (kartta 16), päntä 'lauma' Lavialta (kartta 20) ja (tehdä :) tejen 'teen' Sodankylästä (kartta 39).

Foneettisia paikallisuuksia edustaa esimerkiksi Tampereen seudun hämäläismurteen $i: t a ̈$ edeltävä heleä geminaatta- $l$ (halli, kallis; Kettunen 1940b: 236; Virtaranta 1946: 278-279; Jonninen-Niilekselä 1982: 31-32; Mustanoja 2011: 38). Niin ikään tamperelaiseksi tunnistetaan yksitäryisenä pidetty $r$-äänne, joka todellisuudessa voi olla lievästi liudentunut $r$ (Mustanoja \& O'Dell 2004: 24). Yhteen kylään rajoittuvat murteellisuudet lienevät harvinaisia, mutta todellisuudessa takainen $t$ :kään ei ole vain Toroppalan murteen erikoisuus, vaan sitä tavataan laajemminkin Savonlinnan seudulla, esimerkiksi Enonkoskella. Siitä on havaintoja myös Pohjois-Savosta ja Pohjois-Karjalasta. (Palander 2005a: 32; Nupponen 2011: 48, 297.) Idiolektaalisena $d$ :tä muistuttavaa $t:$ tä voi esiintyä savolaismurteiden ulkopuolellakin. Paljon tarinoita on syntynyt muiden muassa Alahärmässä syntyneen ja jatkosodassa kunnostautuneen "mo- numenddaalisen" everstiluutnantti Nikke Pärmin puhetavasta (Koivumäki 1988). Takaisen $t$ :n levikkialuetta onkin hankalaa selvittää siksi, että esiintymisalueillaankaan piirre ei toteudu säännöllisesti eikä kaikkien murteenpuhujien kielessä.

Foneettisille murteellisuuksille on tyypillistä, että murteenpuhujat itse eivät tunnista niitä omassa puheessaan. Sen sijaan muualta kotoisin olevat voivat kiinnittää niihin huomiota. Keväällä 2017 Toroppalan kylässä haastattelemamme paikkakuntalaiset, joista useimpien kielessä takaista $t$ :tä esiintyi, olivat sitä mieltä, että kuulopuheiden mukaan " $d$ ":tä oli kylällä kyllä käytetty joskus aiemmin mutta itse he eivät sitä käyttäneet eivätkä olleet henkilökohtaisesti sitä koskaan kuulleetkaan. Vastaavalla tavalla sellaiset kielenkäyttäjät, joiden murteeseen kuuluu foneettinen yleis- tai erikoisgeminaatio, eivät yleensä havaitse piirrettä ympäristössään eivätkä omassa ääntämyksessään (Kettunen 1930: 23, alav.; Palander 1987: 210-213). Foneettinen äänteellisyys, joka ei aiheuta merkityseroa, jää helposti tiedostamatta, elleivät ulkopuoliset ala asiasta huomautella. Tämä samalla suojaa ilmiötä katoamasta: puheestaan on vaikea karsia piirrettä, josta ei ole edes tietoinen.

\section{Takainen $t$ maallikoiden kuvaamana}

Kansanlingvistiikan tutkijoille on tuttua, että tarkkakorvaiset lingvistisesti kouluttamattomat kielenkäyttäjät pystyvät havaitsemaan aluemurteista hyvinkin pieniä ääntämyksellisiä eroja (Preston 1989: 35-39; Clopper 2010: 206-209). Suomalaiset maallikot ovat kuvanneet murteiden äänteistä erityisesti konsonanttien kvaliteettia. Vokaalien ääntämyksestä on vähemmän havaintoja; kuitenkin eteläsuomalaisen nykypuhekielen takainen $\ddot{a}$ (mennaan Jarvenpaahan) ja hämäläinen pitkän $a$-vokaalin $o$ :maisuus ovat herättäneet huomiota (Mielikäinen \& Palander 2014b: 216-217). Konsonanteista on kom- 
mentoitu varsinkin Tampereen murteen heleää l:ää (Leino 1968: 165; Mielikäinen 2005: 107; Mielikäinen \& Palander 2014a: s.v. l; 2014b: 217). Huomiota on saanut myös päijäthämäläisen Kuhmoisten murteen etinen $l$, jota jämsäläiset naapurit ovat sanoneet lillahtavaksi (Yli-Luukko 1994: 101-102). Pohjois-Karjalan murteen liudentuneesta l:stä eli l:n pehmentämisestä on samoin havaintoja (Mielikäinen \& Palander 2014b: 219). r:n ääntäminen on kiinnittänyt huomiota länsimurteiden alueella: Tampereen murteen $r$ :ää pidetään kovana, rentona, pidennettynä tai täryisenä, Turun ja Porin seudun rää vaikuttavana ja jylisevänä (Mielikäinen \& Palander 2014a: s.v. $r$; 2014b: 219). Eteläsuomalaisessa nykypuhekielessä esiintyy maallikoiden mukaan terävä $s$ eli stadiässä tai city-s (Vaattovaara \& SoininenStojanov 2006: 239, 241-242, 247; Mielikäinen \& Palander 2014b: 220-221).

Takaista, d:mäiseksi kuvattua $t$ :tä maallikot ovat tunnistaneet PohjoisSavon ja Savonlinnan seudun murteista. Pohjois-Savosta tällaisia havaintoja on varpaisjärveläisten kielestä:

(4) [V]arpaisjärveläisillä tulee $d$-vika, eli $t$-kirjaimet ovat $d$ :itä, esimerkiksi Unto on Undo (Rautavaara, Toivanen 2012: 18).

(5) Sitten tuolla [varpaisjärveläisellä] henkilöllä oli hauska ominaisuus puhuat tee vähä niinkun joillakii, joillakii, jotkut savolaiset - puhhuuvat vähä sillee deeks sen. Suaaddaahan duo ollakii vähä--. (Pellikka 2017: 63.)

Savonlinnan seudulla $d$ :mäisen ääntämyksen on katsottu kuuntelutestissä viittaavan muun muassa Enonkosken murteeseen:

(6) Mut sitten kun se tota, tee-kirjainta, korvas tuolla deellä niin, heittäisin että tää on varmaan tuolta, Enonkoskelta olis. - - Et muutehan tää vois olla niinku taas ihan melkein mistä vaan mutta, mut se on minum mielestä siinä aika semmosta tunnusomaista. (Pellikka 2017: 64.)

Seuraavissa huomioissa takainen $t$ yhdistetään nimenomaan Toroppalan kylään:

(7) Mie panin [kuuntelutestissä Savonrannan näytteen kartalla kohtaan] Kerimäki. Siihe, siihe ja, sen tähe et tuota, se sano duoda duoda ni se ol niinku sanottii ennen että, Toroppalan dee. Ja Toroppala kuulu, kuuluu Kerimäkkee. (Tamminen 2017: 45.)

(8) Toroppalan d on muuten jo klassikko: Kerimäen Toroppalan d:tä eivät murretutkijatkaan meinanneet aluksi uskoa vaan luulivat sen kuuluvan yksilömurteeseen. $\mathrm{Mi}$ nua paikkakunnalle muutettuani $\mathrm{d}$ nauratti, jouduin $\mathrm{mm}$. ostamaan kaupasta "edikeddejä". (Villitystä Savonlinnan seudulla. Blogi 20.4.2010.)

(9) Kermäin t on "Doroppalan (Toroppalan) murretta" ja on vahvasti paikk[ak]untalaisten puheessa kuultavissa. Itä-Suomesta kotoisin oleva näyttelijähän toi ilmaisun kansan tietoisuuteen muutama vuosi sitten lauantai-illan viihdeohjelmassa. (Kotus-blogi, kommentti nimimerkiltä Muallikko isolta kirkolta, 3.4.2014.)

Esimerkissä 9 viitataan savonlinnalaistaustaiseen näyttelijä Kari Hietalahteen, joka on lainannut takaisen $t$ :n kahden näyttelemänsä fiktiivisen hahmon kieleen. Toinen näistä on Yle TV2 -kanavalla esitetyn Pasila-nimisen piirrosanimaatiosarjan 
ylikomisario Rauno Repomies, joka sai puheeseensa takaisen $t$ :n ikänsä perusteella: Hietalahden mukaan puhetapa sopi vanhalle miehelle. Toinen Hietalahden näyttelemä henkilö on Putoussketsiohjelmassa vuonna 2012 esiintynyt "tiploomi-insinööri". Esittäytyessään tämä kertoikin olevansa Toroppalasta, mikä on edesauttanut puhetavan yleistä yhdistämistä Toroppalan kylään.

Kuitenkin jo kymmeniä vuosia aiemmin Toroppalan $t$ :stä on kerrottu seuraavanlaisia murrekaskuja:

(10) Kerimäen Toroppala on siitä erikoinen savolaiskylä, että siellä esiintyy murteessa $d$ :tä. Haastattelija tuli kylään, meni erään vanhan kyläläisen luo ja sanoi:

- Täällä käytetään kuulemma puheessa $d:$ tä.

Kyläläinen katsoi haastattelijaa kummissaan ja vastasi:

- Daidaa olla duristien darinoida.

(11) Toroppalan kylän jäätelökioskilla kuultua:

- Dopsii.

- Duutti vai dötterö?

(Punttila 2001: 32-33.)

$t$-matkimukset voidaan kutakuinkin iätä. Jäätelökasku on syntynyt aikaisintaan 1960-luvulla, sillä Paulig alkoi valmistaa Topsy-merkkisiä jäätelötuutteja 1960-luvun alussa. ${ }^{1}$ Pirkko Leinon laajassa tutkimuksessa Suomalaiset matkimukset (1968) Toroppalan $t$ :stä ei ole vielä mainintoja; Leinon aineisto on kerätty muun muassa Sanastaja-lehden kyselyin vuosina 1948-1966 (mts. 6-9). Toroppalan murteesta on kyllä oltu tietoisia jo 1960-luvun alkupuolella. Kevättalvella 2017 eräs haastattelemamme toroppalalainen nimittäin kertoi, että kun hän oli

1. Sähköpostiviesti Kaisa Junikalta Pauligin kuluttajapalvelusta 13.3.2017. armeijassa vuosina 1963-1964 ja oli joutunut käymään lääkärissä, lääkäri oli kiinnostunut hänen murteestaan kuultuaan, että hän oli Toroppalasta. Lääkäri oli sitten tarkoituksella jututtanut miestä ja luultavasti tarkkaillut tämän murretta.

Miksi Toroppalan $t$ tunnetaan? Yksi syy lienee se, että ilmaus Toroppalan $t$ kertoo alkusointuisena jo suoraan paikkakunnan, mihin piirre yhdistyy. Murrematkimuksille on tyypillistä sijoittaa matkittava ilmiö paikannimeen. Tällaisia murrepiirteen jäljittelyjä ovat muiden muassa väljien vokaalien aa ja ää suppeampaa ääntämystä imitoiva Kankoonpee, svaavokaalia korostava Pohojanmaa ja diftonginreduktiota ivaileva Laakaa. Uusiin paikannimimatkimuksiin kuuluvat Jyvääskylää, jolla jäljitellään toisen tavun lyhyen vokaalin puolipituutta, ja illatiivimuoto Turkkusse, joka tosin ei noudata todellista lounaismurretta. (Mielikäinen 2006: 99, 205-211.) Vaikka takainen $t$ olisi tuttu muistakin Kerimäen kylistä, Jouhenniemen, Ylä-Kuonan tai Simpalan $t$ :tä tuskin muistettaisiin kansanlingvistisenä käsitteenä.

Matkimuksilla on taipumus ajan saatossa muuttua. Esimerkiksi Oulun murteen imitaatio ookko nä(ä) Oulusta on saanut sellaisia jatkokysymyksiä kuin juokko nää pillillä piimää, juokkona viinaa, pelekääkkö nää polliisia ja syökkö nää jellonia (Mielikäinen 2005: 101-102; Palander 2011: 156). Toroppalalaista jäätelönmyyjää imitoiva matkimuskin on jo saanut toisinnon: Duutti, dopsy vai dötterö? - Ei ku dikku. Matkimuksen kehittyminen ja variointi osoittavat, että sanomus on käytössä ja elää. Matkimuksilla ei kuitenkaan voida säilyttää murrepiirteitä vaan päinvastoin: aiemmin tiedostamattomasta ilmiöstä voi näin tulla murteenpuhujien itsensä havaitsema, mikä voi johtaa piirteen kartteluun. Tällä tavoin on selitetty esimerkiksi $t$ :n heikon asteen hämäläisen variantin, l:n, väistymistä 1800-1900-luvulla ja korvautumista muo- 
dikkaammalla $r$ :llä (Virtaranta 1946: 107110; 1958: 215-216).

Kun Toroppalan murteen takaista $t$ :tä jäljitellään liioittelevasti $d: 1 l a ̈$, eräät eilingvistit sekoittavat foneettisesti poikkeavan /t/:n foneemiin /d/. Keväällä 2017 tapaamamme Toroppalassa syntynyt ja kasvanut kyläläinen kertoi, että kansakoulunopettaja oli kertojan lapsuudessa joutunut puuttumaan erään koulupojan kieleen, jossa $d: t$ ja $t$ :t menivät sekaisin. Nähtävästi savolaismurretta puhunut poika ei ole osannut sijoittaa kirjakielen $d$ :tä oikeisiin äänneympäristöihin; tarkempaa tietoa ei ole, koskiko sekaannus puhuttua vai kirjoitettua kieltä. Poika on siis saattanut tuottaa hyperkorrektisti $d$ :tä sellaisiin muotoihin, joihin se ei kuulu, tai on $d$ :tä tavoitellessaan tuottanut $t$ :n. Kummankin tyyppisistä erehdyksistä on olemassa matkimuksia ja kielikaskuja (esim. Leino 1968: 77-78). Ei-lingvistien tulkinnan mukaan takainen $t$ olisikin siten merkitysoppositiossa/t/:n kanssa, mikä ei pidä paikkaansa.

\section{Toroppalan t:n tulevaisuus?}

Foneettisena murteellisuutena takainen $t$ voi Toroppalassa säilyä ainakin niin kauan kuin kylässä on syntyperäisiä asukkaita. Kuten muuallakin maaseutukylissä, myös Toroppalassa väki ikääntyy. Nuoret ovat pääosin siirtyneet opiskelemaan ja työelämään muualle, ja samalla kylän palvelutkin ovat loppuneet. Toroppalan alakoulu lakkautettiin vuonna 2010, eikä kylällä ole enää kauppaakaan. Kyläläiset asioivat nykyään joko Kerimäen kirkolla tai Savonlinnan kaupunkikeskuksessa, joihin sentään on linja-autoyhteys. Toroppalaan on muuttanut uusia asukkaita muualta, mutta heillä ei välttämättä ole syntymäsiteitä alueen murteeseen. Nykyaikana kyläyhteisöt eivät enää toimi samalla tavoin kuin vielä $30-40$ vuotta sitten. Tuolloin asukkailla oli kiinteät keskinäiset kontaktit: kaikki tunsivat toisensa, ja naapureita tavattiin jopa useita kertoja päivässä, mikä oli omiaan säilyttämään paikallista murretta. Nykyään uusiin naapureihin ei tutustuta yhtä hyvin, ja työikäisille tärkeät yhteisöt saattavat sijaita kaukanakin asuinympäristöstä.

Joskus murrepiirteet elävät kuitenkin sitkeämmin kuin uskotaankaan. Esimerkiksi loppu-k:n on todettu olleen vähittäin väistymässä savolaismurteista 1800- ja 190o-lukujen aikana siten, että sen viimeisiä esiintymisalueita on ollut Pohjois-Karjala (Itkonen 1965: 198-210). 180o-luvun lopulla syntyneillä pohjoiskarjalaisilla $-k$ :n esiintyminen on jo vaihdellut niin, että toisilla $-k$ on ollut säännöllistä, toisilla taas satunnaista. Eniten $-k$ :ta on esiintynyt Pohjois-Karjalan keski- ja itäosissa. (Forsberg 1988: 19-20.) $k$-loppuisia muotoja voi silti edelleen, 20oo-luvullakin, kuulla Pohjois-Karjalan vanhemmalla väestöllä. Myös ei-lingvistit tietävät, että - $k$ kuuluu erityisesti maakunnan itäosien murteeseen (Mielikäinen \& Palander 2014b: 122, 180; Palander 2015: 57). Takaisen $t$ :n kaltaisella foneettisella ilmiöllä lienee vielä paremmat mahdollisuudet säilyä vuosikymmenten päähän tulevaisuuteen.

Vielä emme tiedä, missä vaiheessa Toroppalan $t: n$ matkimukset muuttuvat suulliseksi perinteeksi, joka ei enää vastaa todellista tilannetta. Matkimukset pitävät yllä ja levittävät tietoisuutta murteellisuuksista. Nyky-Suomessa television viihdesarjat ja muutkin sähköiset mediat nostavat aika ajoin tehokkaasti murreilmiöitä kansan tietoisuuteen - jopa niin, että niiden välittämään epäaitoonkin kuvaan uskotaan (Palander 2005b: 87-88). Murrepiirteestä voi tällöin tulla sosiaalinen indeksi: puhuja tunnistetaan sen avulla tiettyyn ryhmään kuuluvaksi (indeksisyyden eri asteista ks. Silverstein 2003; Johnson, Andrus \& Danielson 2006). Tämä on käynyt ilmi kuuntelutesteissä. Esimerkiksi tieto siitä, että puhuja on kanadalainen, ohjasi testissä kuulemaan puhujan ääntä- 
mät diftongit korkeampina (engl. raised) kuin niissä tapauksissa, joissa puhujan sanottiin olevan yhdysvaltalainen (Niedzielski 1999). Samoin stereotyyppiset käsitykset Tokion murteen vokaalien soinnittomuudesta määräkonteksteissa vaikuttivat testitilanteessa vokaalien havaitsemiseen (Morris 2010). Suomessa taas terävä tai lespaava $s$ yhdistetään nykyään pääkaupunkiseudun nuoriin naisiin, Helsingin seudulta katsottuna erityisesti Itä-Helsinkiin ja joskus myös homomiehiin (Vaattovaara \& Halonen 2015: 56-70; Surkka 2016: 46-48). Jos kuulijalla on käsitys puhujan taustasta, hän saattaa "kuulla" poikkeavanlaatuista s:ää silloinkin, kun sitä ei todellisuudessa esiinny (Vaattovaara \& Halonen mas. 69, 76-77).

Toroppalan $t: n$ julkisuuskuva on miehinen, mikä voi johtua siitä, että Suomessa miehet puhuvat ylipäätään murteellisemmin kuin naiset (esim. Mantila 2004: 326, 328, 330-331). Alkuaan takainen $t$ on kuulunut myös naisten kieleen. Mikäli murteiden tasoittuminen jatkuu samansuuntaisesti kuin tähän asti, Toroppalan $t: n$ voi ennustaa säilyvän pisimpään paikkakuntalaisten miesten savolaispuheessa.

Marjatta Palander etunimi.sukunimi@uef.fi

\section{Lähteet}

Clopper, Cynthia G. 2010: Classification of regional language varieties. - Dennis R. Preston \& Nancy Niedzielski (toim.), A reader in sociophonetics s. 203-221. New York: De Gruyter Mouton.

Forsberg, Hannele 1988: Pohjois-Karjalan murrenäytteitä. Joensuu: Karjalaisen Kulttuurin Edistämissäätiö.

Itkonen, Terho 1965: Proto-Finnic final consonants. Their history in the Finnic languages with particular reference to the Finnish dialects. SUST 138:1. Helsinki: Suomalais-Ugrilainen Seura.
JoHnSON, BARBARA - ANDRUs, JenNiFER \& Danielson, Andrew E. 2006: Mobility, indexicality, and the enregisterment of "Pittsburghese". - Journal of English Linguistics 34 s. 77-104.

JONNINEN-NiILEKSEL Ä, KAIJA 1982: Tampereen puhekieli tutkimuskohteena. - Kaija Jonninen-Niilekselä (toim.), Tampereen puhekieli tutkimuskohteena s. 7-35. Folia fennistica \& linguistica. Tampereen yliopiston Suomen kielen ja yleisen kielitieteen laitoksen julkaisuja 6. Tampere.

Kettunen, LaUri 1930: Suomen murteet II. Murrealueet. SKST 188. Helsinki: Suomalaisen Kirjallisuuden Seura.

— 1940a: Suomen murteet III A. Murrekartasto. SKST 188. Helsinki: Suomalaisen Kirjallisuuden Seura.

— 1940b: Suomen murteet III B. Selityksiä murrekartastoon. SKST 188. Helsinki: Suomalaisen Kirjallisuuden Seura.

Koivumäki, Pentti 1988: Monumenddaalinen Nikke Pärmi. Kuopio: Kustannuskiila oy.

Kotus-blogi. https://www.kotus.fi/nyt/kotusblogi/blogiarkisto/lasse_koskela/lyhyt_ epikriisi.10795.blog. (Blogi julkaistu 31.3. ja kommentti 3.4.2014; luettu 15.3.2017.)

Leino, Pirk ko 1968: Suomalaiset matkimukset. Suomen kielen pro gradu -tutkielma. Helsingin yliopisto.

Mantila, Harri 2004: Murre ja identiteetti. - Virittäjä 108 s. 322-346.

MHA C:1 = Savonlinnan läänin maanmittarin Laurentz Röösin karttakirja Säämingistä, Kerimäeltä, Sulkavalta ja Puumalasta vuosilta 1643-1646. Maanmittaushallituksen arkisto. Helsinki.

Mielikäinen, Aila 2005: Matkimuksista määritelmiin. Miten murteista puhutaan. - Sananjalka 47 s. 98-118.

- 2006: Paikkoihin viittaavat ilmaukset murteiden jäljittelyssä. - Annekatrin Kaivapalu \& Külvi Pruuli (toim.), Lähivertailuja 17 s. 193-216. Jyväskylä Studies in Humanities 53. Jyväskylä: Jyväskylän yliopisto. 
Mielikäinen, Aila - Palander, MarJAT TA 2014a: Miten murteista puhutaan. Kansanlingvistinen sanakirja. Jyväskylän yliopisto, Kielikampus. http://kielikampus.jyu.fi/mitenmurteistapuhutaan/ (17.4.2017).

_ 2014b: Miten suomalaiset puhuvat murteista? Kansanlingvistinen tutkimus metakielestä. Suomi 203. Helsinki: Suomalaisen Kirjallisuuden Seura.

Mielonen, Asko 1993: Vanhan Kerimäen historia I:1. Enonkosken, Kerimäen, Punkaharjun ja Savonrannan historia vuoteen 1865. Enonkosken, Kerimäen, Punkaharjun ja Savonrannan kunnat.

Morris, Midori Yonezawa 2010: Regional stereotypes and the perception of Japanese vowel devoicing. - Dennis R. Preston \& Nancy Niedzielski (toim.), A reader in sociophonetics s. 191-202. New York: De Gruyter Mouton.

Mustanoja, LiIs a 2011: Idiolekti ja sen muuttuminen. Reaaliaikatutkimus Tampereen puhekielestä. Acta Universitatis Tamperensis 1605. Tampere: Tampereen yliopisto.

Mustanoja, Liisa - O’Dell, Michael 2004: Tremulantin ääntämys tamperelaisittain. - Tapio Seppänen, Kari Suomi \& Juhani Toivanen (toim.), Fonetiikan päivät 2004 - The Phonetics Symposium 2004 s. 21-25. Oulu: Oulun yliopisto \& Suomen kielen, informaatiotutkimuksen ja logopedian laitos.

Nahkola, Kari 1998: Paaministeri paatti tanaan. - Virittäjä 102 s. 224-232.

NiedZielski, NANCY 1999: The effects of social information on the perception of sociolinguistic variables. - Journal of Language and Social Psychology 18 s. 62-85.

Nupponen, Anne-Maria 2011: "Savon murre" savolaiskorvin. Kansa murteen havainnoijana. Publications of the University of Eastern Finland. Dissertations in Education, Humanities, and Theology No 11. Joensuu: University of Eastern Finland.
Palander, Marjatta 1987: Suomen itämurteiden erikoisgeminaatio. SKST 455. Helsinki: Suomalaisen Kirjallisuuden Seura.

- 1993: Vanhan Kerimäen murre. - Vanhan Kerimäen historia I:2. Erillisartikkelit s. 217-246. Enonkosken, Kerimäen, Punkaharjun ja Savonrannan kunnat.

1996: Vaihtelu Savonlinnan seudun välimurteissa. SKST 648. Helsinki: Suomalaisen Kirjallisuuden Seura.

2001: Välimurteiden idiolektit. Variaatio Savonlinnan seudun yksilömurteissa. - Virittäjä 105 s. 22-43.

_ 2005a: Lapsuudesta keski-ikään. Seuruututkimus itäsavolaisen yksilömurteen kehityksestä. Suomi 191. Helsinki: Suomalaisen Kirjallisuuden Seura. 2005b: Muu suomi karjalaisten silmin. - Marjatta Palander \& Anne-Maria Nupponen (toim.), Monenlaiset karjalaiset. Suomen karjalaisten kielellinen identiteetti s. 56-9o. Studia Carelica Humanistica 20. Joensuu: Joensuun yliopiston humanistinen tiedekunta.

_ 2011: Itä- ja eteläsuomalaisten murrekäsitykset. Suomi 20o. Helsinki: Suomalaisen Kirjallisuuden Seura.

_ 2015: Rajakarjalaistaustaisten ja muiden suomalaisten mielikuvia karjalasta.

- Virittäjä 119 s. 34-66.

Pellikka, Anninna 2017: Savolaiset Pohjois- ja Etelä-Savon murteiden tunnistajina ja havainnoijina. Suomen kielen pro gradu -tutkielma. Itä-Suomen yliopisto.

Preston, Dennis R. 1989: Perceptual dialectology. Nonlinguists' views of areal linguistics. Dordrecht: Foris Publications.

Punttila, Matti 2001: Pilkettä silmäkulmaan. Kielikaskuista sanaleikkeihin. Helsinki: WSOY.

SARVAS, LEENA 1980: Lapinlahden murretta. Suomen kielen näytteitä 9. Helsinki: Kotimaisten kielten tutkimuskeskus.

Silverstein, Michael 2003: Indexical order and the dialectics of sociolinguistic 
life. - Language \& Communication 23

s. 193-229.

SKNA = Suomen kielen nauhoitearkisto.

Kotimaisten kielten keskus. Helsinki.

SKST $=$ Suomalaisen Kirjallisuuden Seuran

Toimituksia.

SurkкA, SANni 2016: Tyylikästä lässytys-

tä. Homoseksuaali mies kielellisenä stereotyyppinä ja identiteettinä. Suomen kielen pro gradu -tutkielma. Helsingin yliopisto.

SUST = Suomalais-Ugrilaisen Seuran Toimituksia.

TAmminen, Henry 2017: Tämän kuluman murretta jotenkii. Kuinka savonlinnalaiset tunnistavat kotimurteensa erityispiirteet? Suomen kielen pro gradu -tutkielma. Itä-Suomen yliopisto.

ToIvAnEN, JAANA 2012: Rautavaaralaismaallikoiden murrekäsityksiä. Suomen kielen seminaariesitelmä. Itä-Suomen yliopisto.

VaAttovaara, Johanna - Halonen, MIA 2015: Missä on ässä? "Stadilaisen $s: n$ " helsinkiläisyydestä. - Marja-Leena Sorjonen, Anu Rouhikoski \& Heini Lehtonen (toim.), Helsingissä puhuttavat suomet. Kielen indeksisyys ja sosiaaliset identiteetit s. 40-83. SKST 1310. Helsinki: Suomalaisen Kirjallisuuden Seura.

VaAt tovaARa, Johanna - SoininenStojanov, Henna 2006: Pääkaupunkiseudulla kasvaneiden kotiseuturajaukset ja kielelliset asenteet. - Kaisu Juusela \& Katariina Nisula (toim.), Helsinki kieliyhteisönä s. 223-254. Helsinki: Helsingin yliopiston suomen kielen ja kotimaisen kirjallisuuden laitos.

Villitystä Savonlinnan seudulla. Blogi. http:// notkolla.blogspot.fi/2010/o4/vihersijo-viime-viikolla-windmill-in.html. (Blogikirjoitus päivätty 20.4.2010; luettu 15.3.2017.)

Virtaranta, PertTi 1946: Länsiyläsatakuntalaisten murteiden äännehistoria I. Konsonantit. SKST 230. Helsinki: Suomalaisen Kirjallisuuden Seura.

— 1958: Pääpainollisen tavun jälkeisen soinnillisen dentaalispirantin edustus suomen murteissa. SKST 252. Helsinki: Suomalaisen Kirjallisuuden Seura.

Yli-LuUkкo, Eeva 1994: Jämsän äijän oma kuva. - Ilkka Savijärvi \& Eeva Yli-Luukko, Jämsän äijän murrekirja s. 45-20o. SKST 618. Helsinki: Suomalaisen Kirjallisuuden Seura.

\section{Puheentunnistus ja kielenoppiminen työssä: Uusia mahdollisuuksia kartoittamassa}

Luonnollista kieltä käsittelevä tietokone on ollut pitkään fennististen vitsien kohde. Tietokonekäännöksistä on etsitty päättömiä esimerkkejä, puheentunnistusohjelmien väärille tulkinnoille on naureskeltu ja termeille konekäännöskieli ja Google Translate -kieli on vakiintunut vähemmän mairittelevia merkityksiä. Tietotekniikan kehittyminen - erityi- sesti suuriin datamääriin perustuva tutkimus ja sovellukset - on kuitenkin muuttanut tilannetta merkittävästi. Humanismi ja tietokoneet ovat kohdanneet toisensa, minkä osoittavat viime aikoina perustetut digitaalisen humanismin oppituolit. Fennistit ovat perinteisesti käyttäneet laajoja korpuksia, mutta nyt on alettu pohtia myös, miten koneiden kielenprosessointi- 